\title{
Design of travel angle control of quanser bench-top helicopter using mamdani-based fuzzy logic controller
}

\author{
Hasmah Mansor ${ }^{1}$, Tun Mohamad Aqil Mohamad Fadzir², Teddy Surya Gunawan ${ }^{3}$, Zuriati Janin ${ }^{4}$ \\ ${ }^{1,2,3}$ Department of Electrical and Computer Enginering, International Islamic University Malaysia, Malaysia \\ ${ }^{3}$ School of Electrical Engineering and Telecommunications, University of New South Wales, Australia \\ ${ }^{4}$ Faculty of Electrical Engineering, Universiti Teknologi MARA, Malaysia
}

\section{Article Info}

Article history:

Received Jun 10, 2019

Revised Aug 11, 2019

Accepted Aug 25, 2019

\section{Keywords:}

Bench-top helicopter

Linear quadratic integral

controller

Mamdani-based fuzzy logic

controller

Travel angle control

\begin{abstract}
This research focuses on travel angle control of a laboratory scale bench-top helicopter developed by Quanser Inc. Bench top-helicopter is usually used by engineers and researchers to test their designed controllers before applying to the actual helicopter. Bench-top helicopter has the same behavior as the real helicopter, with 3 degree of freedom. The bench-top helicopter is mounted on a flat surface with two rotors that depends on the voltage supplied to change the direction of the helicopter in 3 different angles. The movement of the helicopter is based on the direction of three-different angles; travel, pitch and yaw angles. The existing Linear Quadratic Regulator-Integral controller used by Quanser Inc has some limitations in terms of tracking capability and settling time; therefore, this research is proposed. The objective of this research is to develop Mamdani-based Fuzzy Logic Controller for travel angle control of bench-top helicopter. Performance comparison has been done with the existing Linear Quadratic Regulator-Integral controller in both simulation and hardware. From the test results, it was found that the performance of Fuzzy Logic Controller is better than LQR-I controller especially for closed-loop simulation at desired angle of $30^{\circ}$. The percentage of overshoot of the Fuzzy Logic Controller has been improved from the existing controller which is $4.912 \%$ compared to $7.002 \%$ for LQR-I.
\end{abstract}

Copyright $@ 2020$ Institute of Advanced Engineering and Science. All rights reserved.

\section{Corresponding Author:}

Hasmah Mansor,

Department of Electrical and Computer Engineering,

Internation Islamic University Malaysia, Malaysia.

Email: hasmahm@iium.edu.my

\section{INTRODUCTION}

Many aerial vehicles used conventional methods such as Propotional Integral Derivative (PID), Linear Quadratic Regulator (LQR) or other controller to control travel axis, pitch axis and elevation axis. In the past, conventional controller was very efficient and reliable as a controller for aerial vehicles however mathematical formulation and computation have been increased due to more advanced aerial vehicles. As a result, the controller takes a longer time to process. Quanser bench-top helicopter has been using LQR for some time, however it may not very efficient today because of the increase in users' demand and expectation due to rapid development of technology. From the previous research in [1], LQR-PID based controller has lower accuracy and rapidity when implemented on bench-top helicopter. In [2], multiple-surface sliding controller (MSSC) has been proposed to solve the accuracy and rapidity problem. Although MSSC was proven to perform better than PID controller, to obtain the desired equation and gain have involved complex mathematical calculation. Integration of PID and fuzzy controller has been proposed in $[3,4]$.

Fuzzy Logic Controller, a type of intelligent controller was introduced in 1960s, based on human reasoning. Fuzzy Logic Contoller has been used by many industrial applications and research. Some of the 
proposed applications are water quality index, temperature control, robot arm and control of grain dryer plant, to name a few [5-8]. In transportation, Fuzzy Logic Controller is worth to explore.

Fuzzy Logic Controller operates based on human reasoning and variables with uncertainty. Fuzzy Logic uses membership function from the inputs and pre-defined rules table to calculate the output [9]. Fuzzy logic can calculate the operation with more than one input [8-12]. There are several types of inference methods that were introduced to develop Fuzzy Logic Controller. The most common methods that were used are Sugeno and Mamdani based inference method [13]. Mamdani-based Fuzzy Logic Controller is also known for restraining expert knowledge. It also allowed the operation to be more sensitive, similar to human characteristics. Nevertheless, Mamdani based Fuzzy Logic Controller is not suitable to be used for interfaces based on computational method. Sugeno based Fuzzy Logic Controller operates with computational mathematical equation and it is suitable for adaptive technique and optimization that appropriate for control problems, mostly for dynamic non-linear systems [14].

Fuzzification and De-fuzzification are two main operations in Fuzzy Logic Controller. Fuzzification is the operation that can translate mathematical input value into the membership function of Fuzzy Logic [8], [15]. On the other hand, De-fuzzification is the operation that converts the output from Fuzzy Logic membership function into the value that can be used by the controller [16, 17]. The application of Fuzzy Logic Controller for aerial vehicle is not well investigated. Therefore, this research proposed a control of bench-top helicopter, particularly the travel angle using Mamdani-based Fuzzy Logic Controller.

\section{RESEARCH METHODOLOGY}

\subsection{Bench-top Helicopter Platform}

Bench-top helicopter is a laboratory scale helicopter usually used for experimental purposes [18]. The bench-top helicopter has fundamentally same dynamic behavior as a real helicopter with high uncertainty. The uncertainty that may happened is in form of different restriction and can be exaggerated by disturbances; for example strong wing and hardware tear and wear. Achieving high performance control over 3-DOF helicopter is a difficult due to some challenges. Bench-top helicopter is an under actuated system, which means number of control inputs are less than number of outputs to be controlled; in this case it has two control inputs and three outputs [19]. In this project, one output which is travel angle is considered. There are also challenges in terms of correlation between pitch and travel, and also parameter variations that contribute to uncertainty of the helicopter model. The parameter variations include flight altitude, fuel consumption, airspeed and amount of load [20].

Figure 1 shows three Degree of Freedom (3DOF) helicopter used in this research. The bench-top helicopter consists of two DC motor that is mounted at the end of the frame and two drive propellers [21]. The helicopter also can move in three direction of angles which are elevation, pitch and travel angles. The 3DOF two motor is set up in parallel and it pushes trajectory was normal to the frame. The helicopter frame is mounted to the joint at the center and it is free to pitch at the center. The other end of the helicopter is mounted with the weight that acts as a counterweight to make the helicopter get the effective weight to be lifted by using the trust of the two motors. Figure 2 shows bench-top helicopter at starting position.

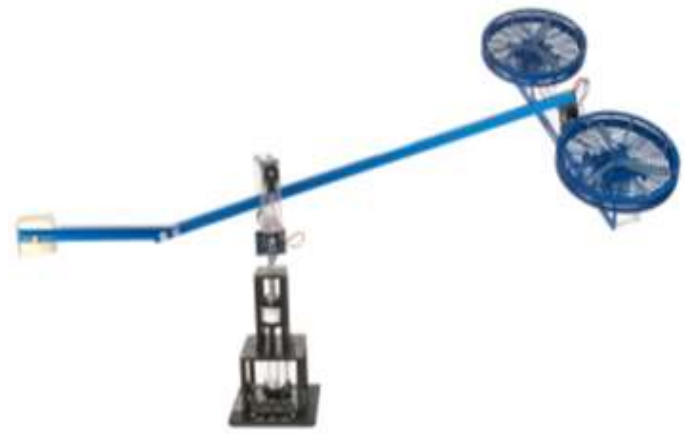

Figure 1. Bench-Top helicopter platform [21]

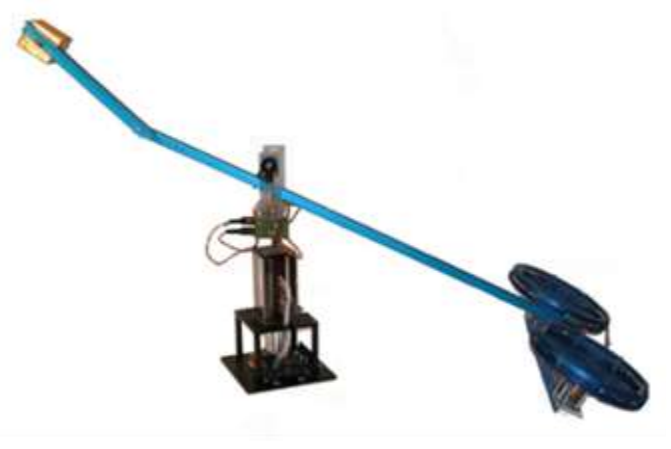

Figure 2. Bench-Top helicopter at starting position [21]

The change of angle for bench-top helicopter is controlled by the controller where the existing controller is LQR-I. The controller processes the angle set by the user, then convert into electrical energy that power up DC rotor which is also the propeller of the helicopter. The total force, F that causes the helicopter 
to change the angle (measured by encoder) is due to helicopter's aerodynamics. The propeller lifts the helicopter's body by the arm that is mounted with a counterweight. The angles of benchtop helicopter is measured by the absolute encoder and controlled by controller.

This research focused on travel angle control only. The type of controller proposed in this research is Mamdani-based Fuzzy Logic Controller. The performance evaluation of the bench-top helicopter was done using Simulink, Quarc and Fuzzy logic toolbox in MATLAB. Comparison of results was performed between the proposed controller and existing controller (LQR-I). Partial results with brief explanation of experimental work were referred in [18].

\subsection{Fuzzy Logic Controller Design}

The first step in Fuzzy Logic Controller design is to define Fuzzy rules. In this research, two inpus and one output Fuzzy Logic Controller has been designed. The inputs are Error and Change of Error whereas the output is Response. Error indicates the difference between desired angle and the actual angle measured by absolute encoder. Each input and output has their own membership function. The membership function is the range of subnet used to define fuzzy rules $[23,24]$. In this research, both inputs consist of three membership functions named $\{\mathrm{NEG}, \mathrm{Z}, \mathrm{POS}\}$ and the output consist of five memberships function named $\{\mathrm{VS}, \mathrm{S}, \mathrm{M}, \mathrm{F}$, VF . The Fuzzy rules were set after all membership functions were defined, based on the dynamic behaviour of the bench-top helicopter.

In this research, nine fuzzy rules have been developed, as shown in Table 1. The fuzzy rules are set using Matlab Fuzzy Logic Toolbox as shown in Figure 3. "and" method is used to compare the two inputs in fuzzification operation whereas "centroid" method is used to obtain the results in de-fuzzification [25].

Table 1. Fuzzy Rule Table

\begin{tabular}{cccc}
\hline $\begin{array}{l}\text { Change } \\
\text { of Error }\end{array}$ & NEG & Error & POS \\
\hline NEG & VS & S & M \\
Z & S & M & F \\
POS & M & F & VF \\
\hline Note: & & \\
VS - Very Slow & & \\
S - Slow & & \\
M - Medium & & \\
F- Fast & & \\
VF- Very Fast & &
\end{tabular}

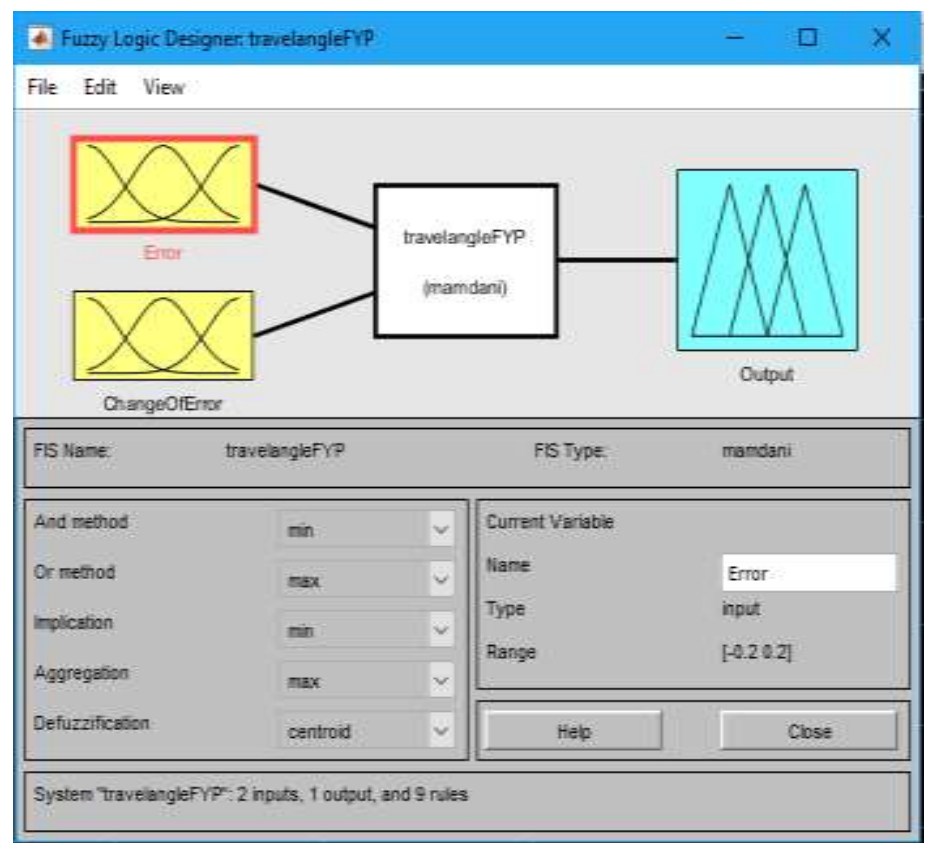

Figure 3. Fuzzy logic designer in matlab

\subsection{Fuzzy Logic Controller for a Closed-Loop System}

The proposed Fuzzy Logic Controller has been tested against bench-marked LQR-I controller on Quanser 3DOF helicopter via closed-loop system simulation. The overall block diagram of the simulation is shown in Figure 4.

Fuzzy Logic Controller has been used to control the back motor of the 3-DOF helicopter as shown in Figure 5. The fuzzy logic travel controller block subsystem is shown in Figure 6. For real hardware test, Quarc toolbox has been used where q4 data acquisition card was connected to the Quanser 3-DOF bench-top helicopter, referring to User Manual [17]. 
Quanser 3-DOF Helicopter:

Closed-Ioop System Simulation

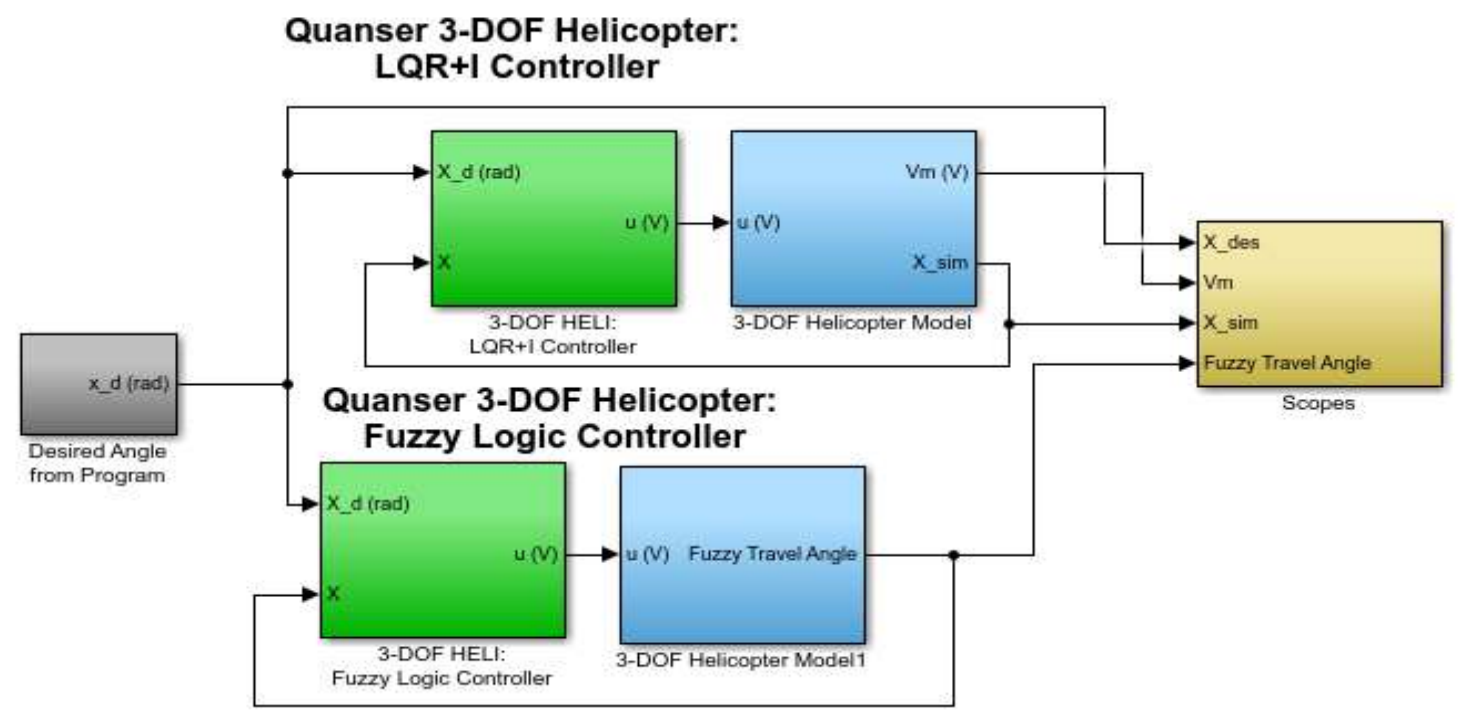

Figure 4. A closed-loop system simulation for travel angle control

3-DOF Helicopter: Position Controller

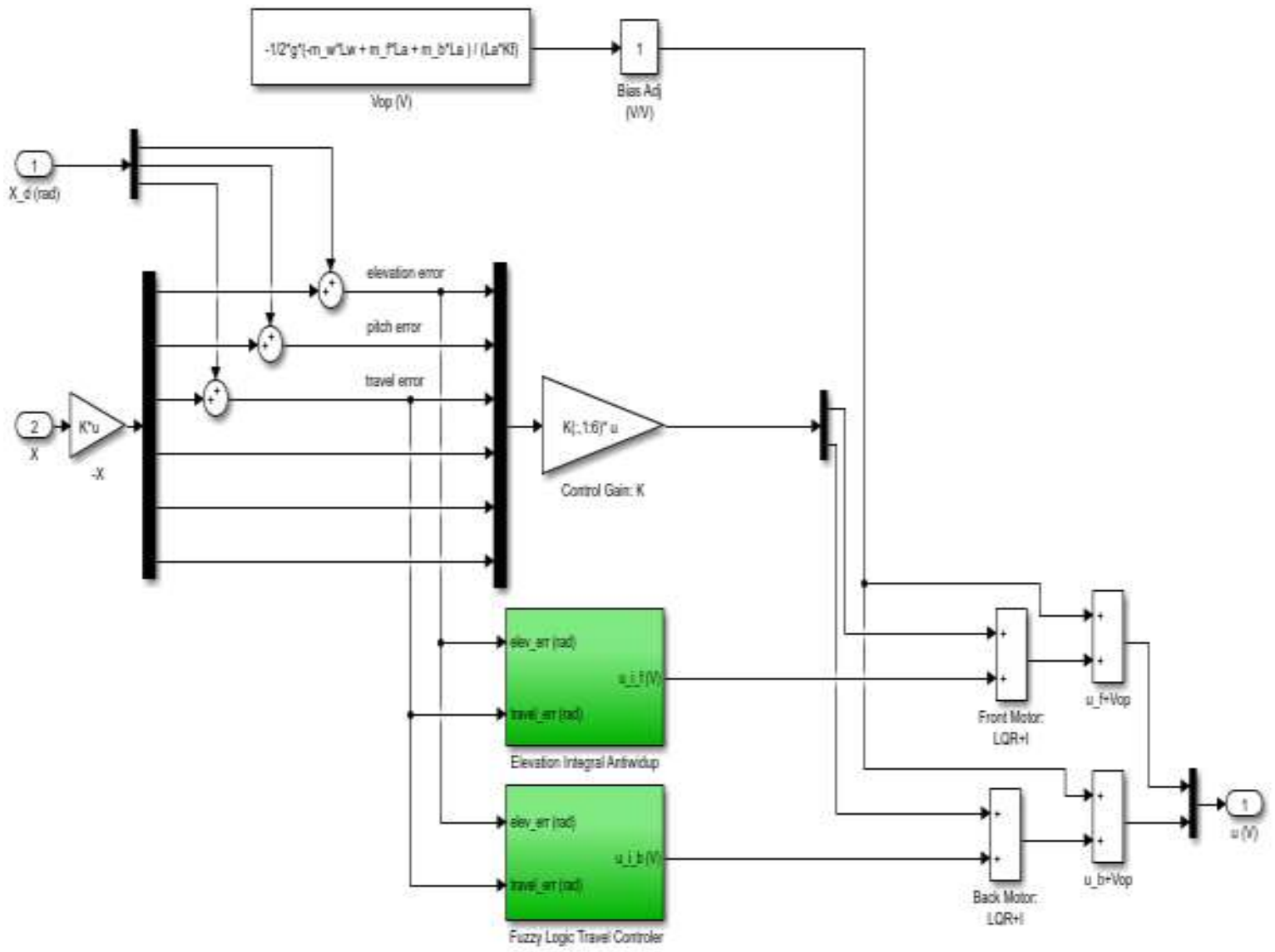

Figure 5. Position controller of bench-top helicopter 


\section{Fuzzy Logic control .}

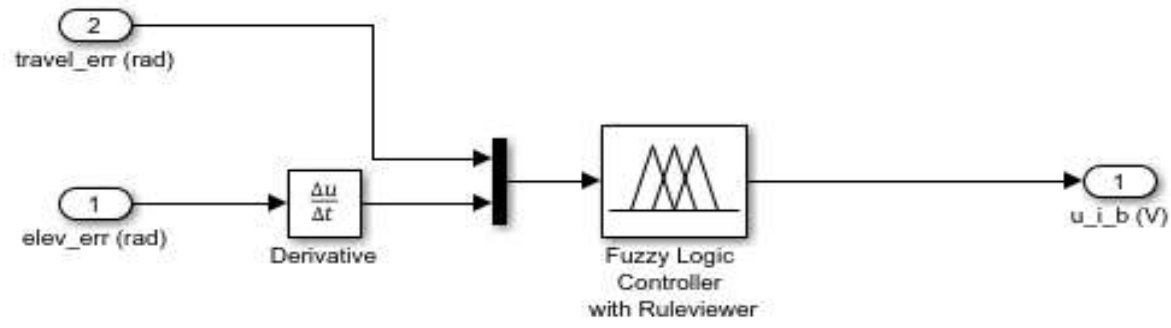

Figure 6. Fuzzy logic controller with anti-windup

\section{RESULTS AND ANALYSIS}

Simulation work and hardware tests have been conducted. Performance of the proposed fuzzy logic controller is presented and analysed in this section.

\subsection{Membership Function Evaluation}

Tuning the membership function is one of the most important part in designing Fuzzy Logic Controller. Fuzzy Logic Controller tracking capability will be more efficient if the membership function is properly tuned. The tuning of membership function can be done in the form of shape, range and position. In this research, triangular and trapezoidal shape have been chosen. In the process of tuning the membership function, the range and position of the membership function were adjusted. The three ranges of error, change of error and output are (-0.2 to 0.2$),(-0.34$ to 0.3$)$ and (-1.65 to 1.65$)$ respectively. Figure $7-9$ show the membership functions proposed in this research.

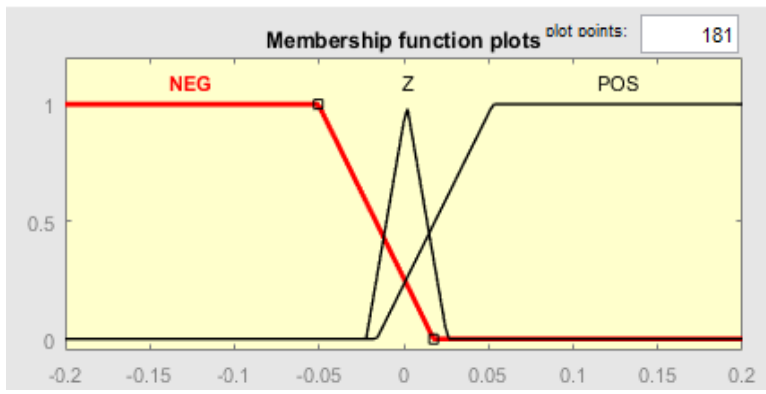

Figure 7. Error membership function

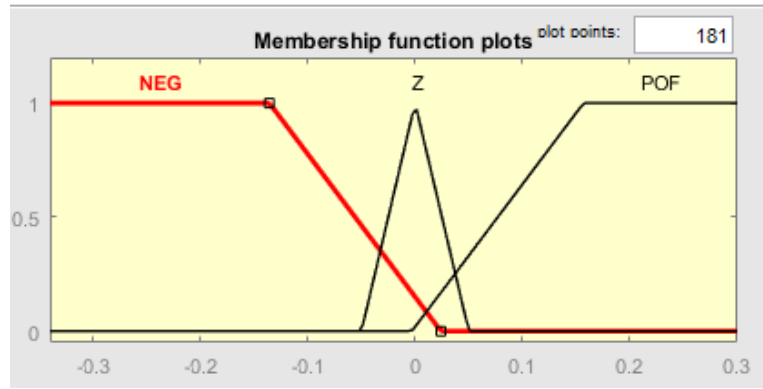

Figure 8. Change of error membership function

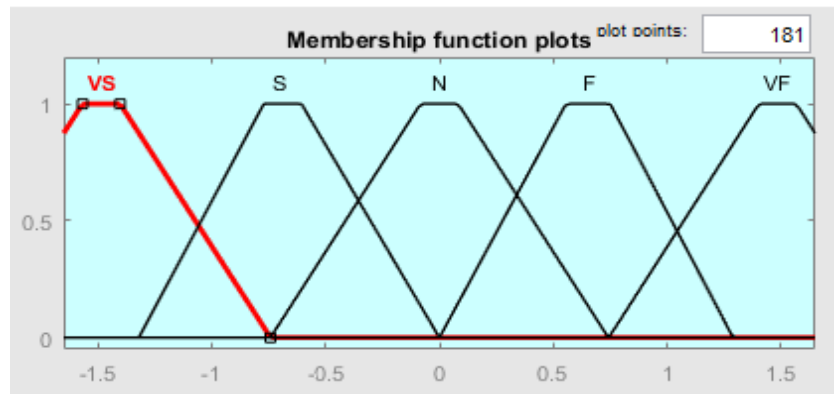

Figure 9. Output membership function

\subsection{Software Simulation}

During the initial test, tracking test was conducted on bench-top helicopter using Mamdani-based fuzzy logic controller. Step input (desired travel angle) was applied to the system as shown in Figure 4. Small step input of angles $6^{\circ}, 7^{\circ}$ and $8^{\circ}$ were set. From the step input, error and change of error were 
calculated. Based on the ranges of both inputs, the membership functions were set and fuzzification process took place. Then the controller manipulated the output based on the 9 rules that has been set (refer to Table 1). Then, de-fuzzification process took place. The output from Fuzzy Logic membership function was converted into the value that can be used by the controller as the controller output. The controller output was fed into the 3-DOF helicopter model to control the plant (helicopter). The results of small step input tests are shown in Figure 10.

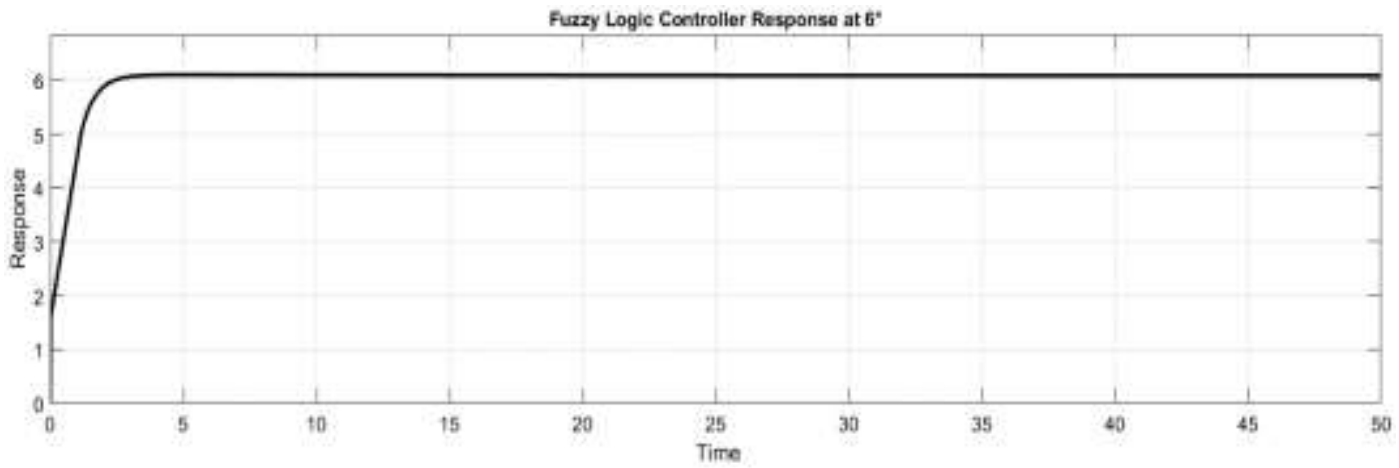

(a) $6^{\circ}$ travel angle

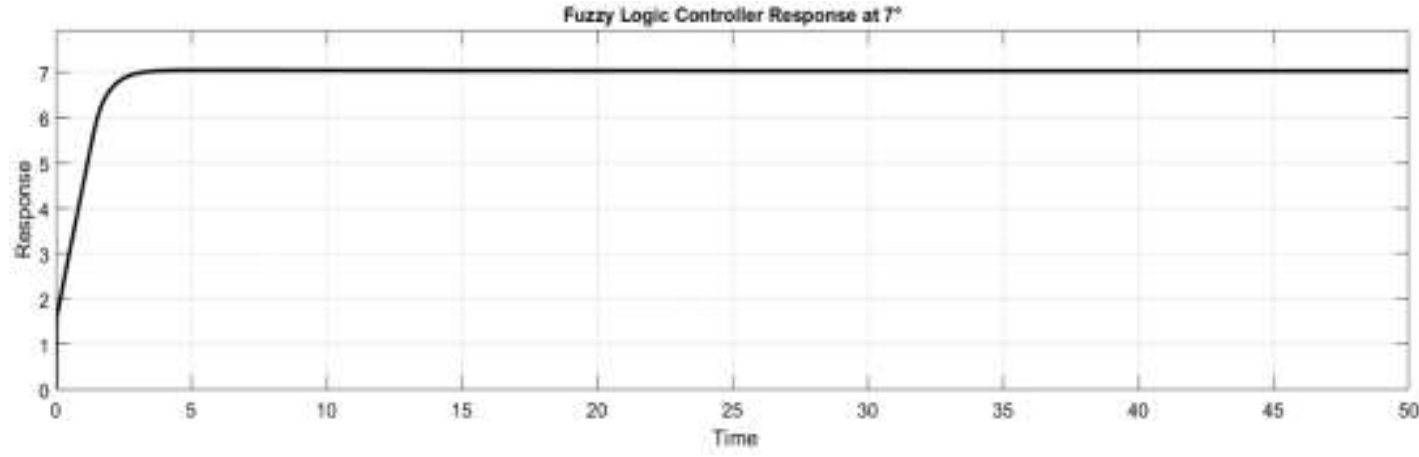

(b) $7^{\circ}$ travel angle

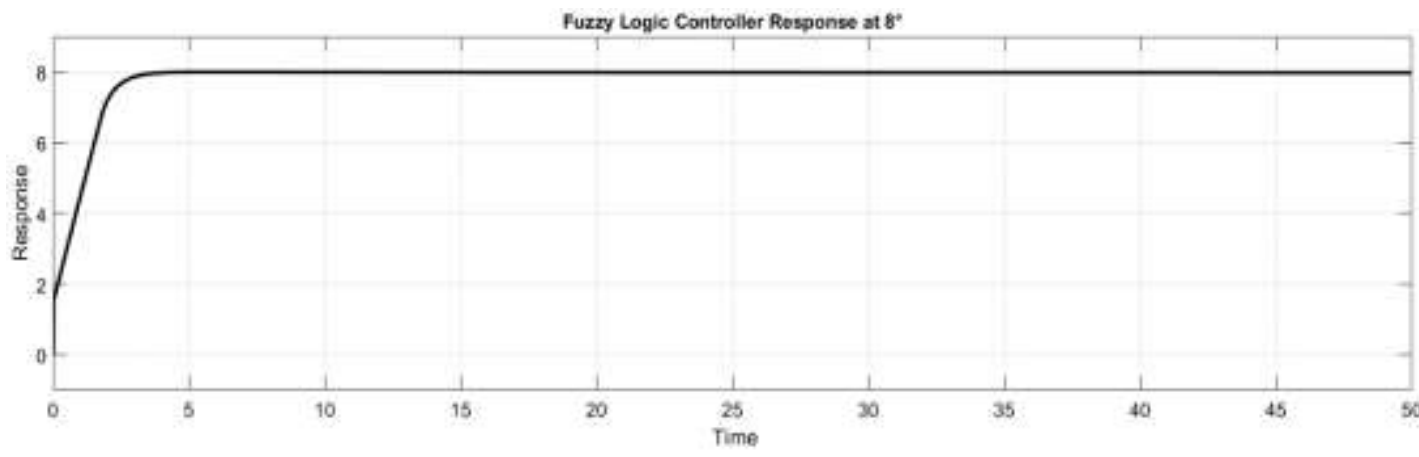

(c) $8^{\circ}$ travel angle

Figure 10. Fuzzy logic controller response of step input at (a) $6^{\circ}$, (b) $7^{\circ}$ and (c) $8^{\circ}$

From the results shown in Figure 10, Fuzzy Logic Controller works very well for tracking small angles. In these 3 different step input tests, there are no percentage of overshoot and almost zero steady state error. The controller adjusted very fast where the settling time for all tests are about $2 \mathrm{~s}$.

The performance fuzzy logic controller was further verified by comparing its performance with PID controller. At desired set point of $7^{\circ}$, the performance comparison was conducted and results is shown in Figure 11. Figure 11 shows that Fuzzy Logic Controller performance was better than PID controller where the settling time of fuzzy logic is faster than PID (3.18s versus 10s) and percentage overshoot is smaller $(0.64 \%$ versus $5 \%)$. However, both controllers have zero steady state error. 


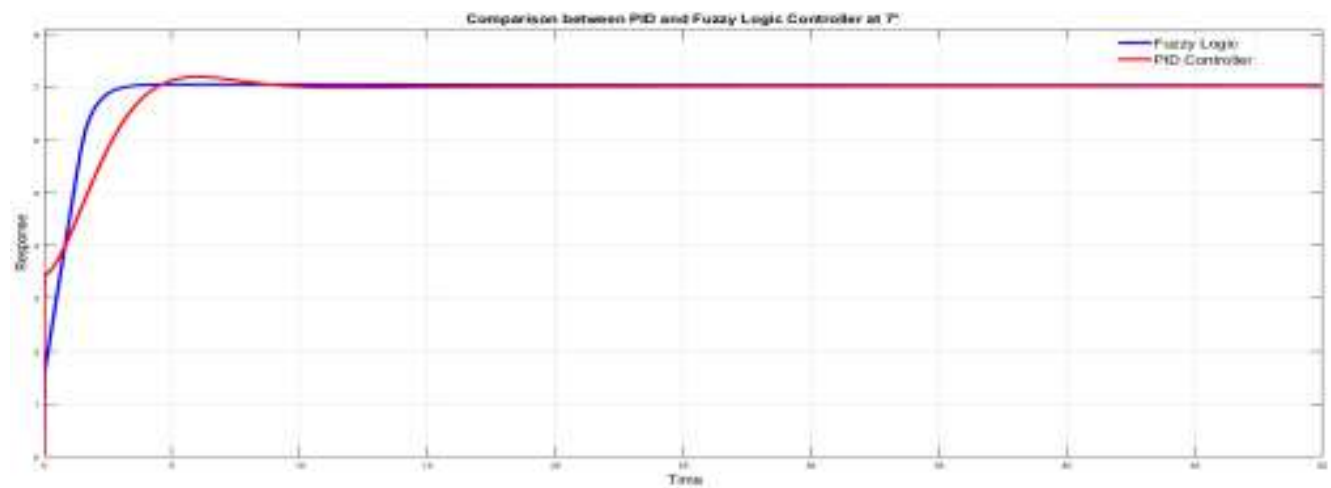

Figure 11. Comparison between PID and fuzzy logic controller at $7^{\circ}$

Next, the closed loop system was tested for higher range of angle i.e. $20^{\circ}, 30^{\circ}$ and 40 . The Fuzzy Logic Controller performance was compared with the LQR-I for analysis purposes. The result of the simulations for angle $20^{\circ}, 30^{\circ}$ and $40^{\circ}$ are shown in Figure $12(\mathrm{a})$, (b), and (c), respectively.

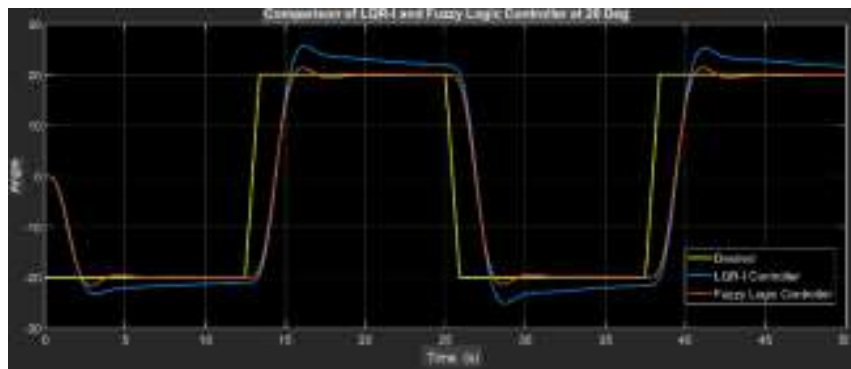

(a) $20^{\circ}$ angle

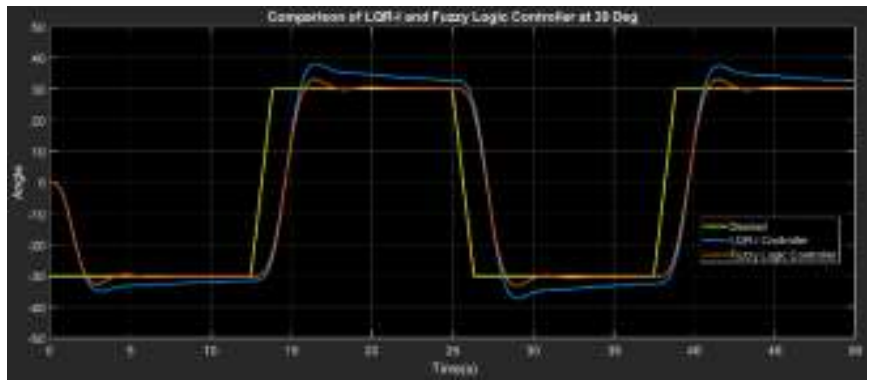

(b) $30^{\circ}$ angle

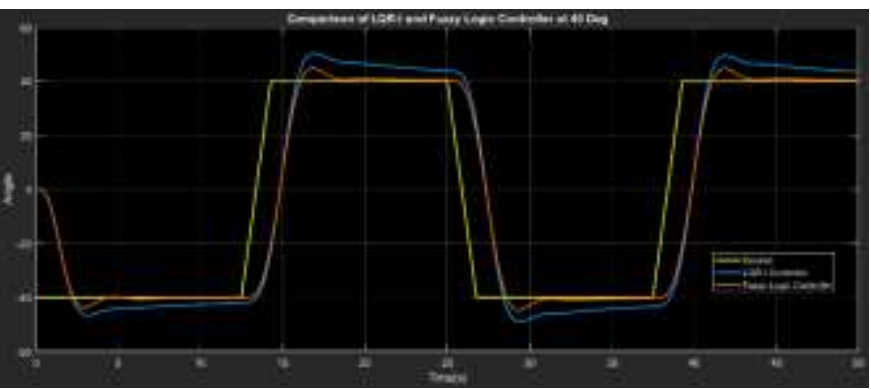

(c) $40^{\circ}$ angle

Figure 12. Comparision between mamdani based fuzzy logic controller and lqr-i at $20^{\circ}, 30^{\circ}$ and $40^{\circ}$ travel angles 
For the travel angle of $20^{\circ}$, Fuzzy Logic Controller produced the output that is close to the desired output with a small percentage overshoot. Figure 12 (a) shows that LQR-I controller produced output that has high steady state error. Fuzzy logic Controller performed better than LQR-I controller in term of percentage overshoot, steady state error and settling time for angle $20^{\circ}$. For the travel angle of $30^{\circ}$, percentage overshoot, settling time and steady state for Fuzzy Logic Controller are lower than LQR-I. Figure 12 (b) shows that Fuzzy logic has small overshoot and undershoot before constant at the same level as desired output. For the travel angle of $40^{\circ}$ as shown in Figure 12 (c), percentage overshoot for Fuzzy Logic Controller is lower than LQR-I. Fuzzy Logic Controller has shorter settling time and almost zero steady state error. The overall results are summarised in Table 2.

Table 2. Summary of Performance Comparison between Fuzzy Logic and LQR-I Controller

\begin{tabular}{cccc}
\hline Desired Angle & & LQR-I & Fuzzy Logic \\
\hline \multirow{2}{*}{$20^{\circ}$} & Percentage Overshoot (\%) & 8.263 & 2.775 \\
& Settling Time (s) & 6.1 & 2.27 \\
& Steady State Error & 1.65 & 0.05 \\
$30^{\circ}$ & Percentage Overshoot (\%) & 7.002 & 4.912 \\
& Settling Time (s) & 5.104 & 2.638 \\
& Steady State Error & 2.53 & 0.12 \\
$40^{\circ}$ & Percentage Overshoot (\%) & 5.707 & 4.886 \\
& Settling Time (s) & 4.170 & 2.839 \\
& Steady State Error & 3.46 & 0.3 \\
\hline
\end{tabular}

Based on simulation results shown in Table 2, steady state error, percentage overshoot and settling time of Fuzzy Logic Controller are lower than LQR-I controller. Therefore, it can be concluded that Fuzzy Logic Controller gives better response than LQR-I controller in controlling travel angle of benchtop helicopter in simulation mode.

\subsection{Actual Hardware Testing}

The performance of Fuzzy Logic Controller via simulation was satisfied. Next, the system was tested on the actual hardware. The system used for the hardware test was closed-loop system that was developed by Quanser Inc. 3DOF bench-top helicopter was used, located at Spacecraft Guidance, Navigation and Control Laboratory, E5, Kulliyyah of Engineering, IIUM. Figure 13 shows the interface between software (Matlab-Simulink) to the actual bench-top helicopter hardware.

\section{Quanser 3 DOF Helicopter: Closed-loop Actual System}

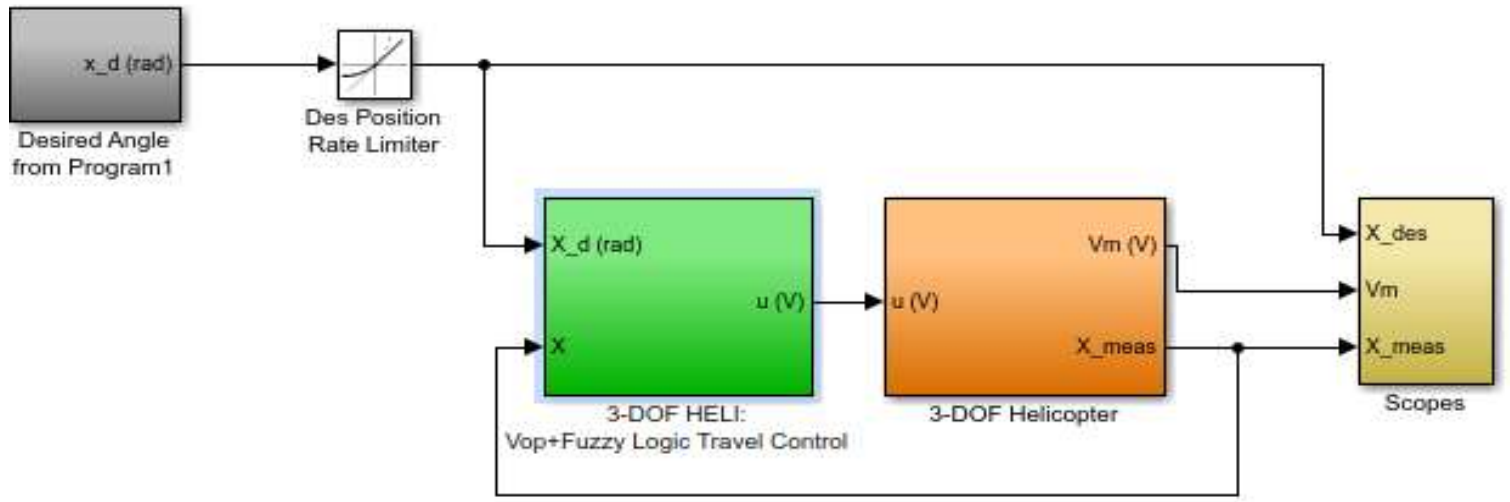

Figure 13. Quanser 3 DOF Helicopter: closed-loop actual system

Travel angle of $30^{\circ}$ was used to test the performance of Fuzzy Logic Controller on the hardware. The result for the hardware test for $30^{\circ}$ travel angle is shown in Figure 14. At every 5 seconds, the graph restart due to limitation of the memory. Based on the results, Fuzzy Logic Controller successfully tracked the desired output with zero steady state error, 4 seconds of settling time and zero percentage of overshoot. 


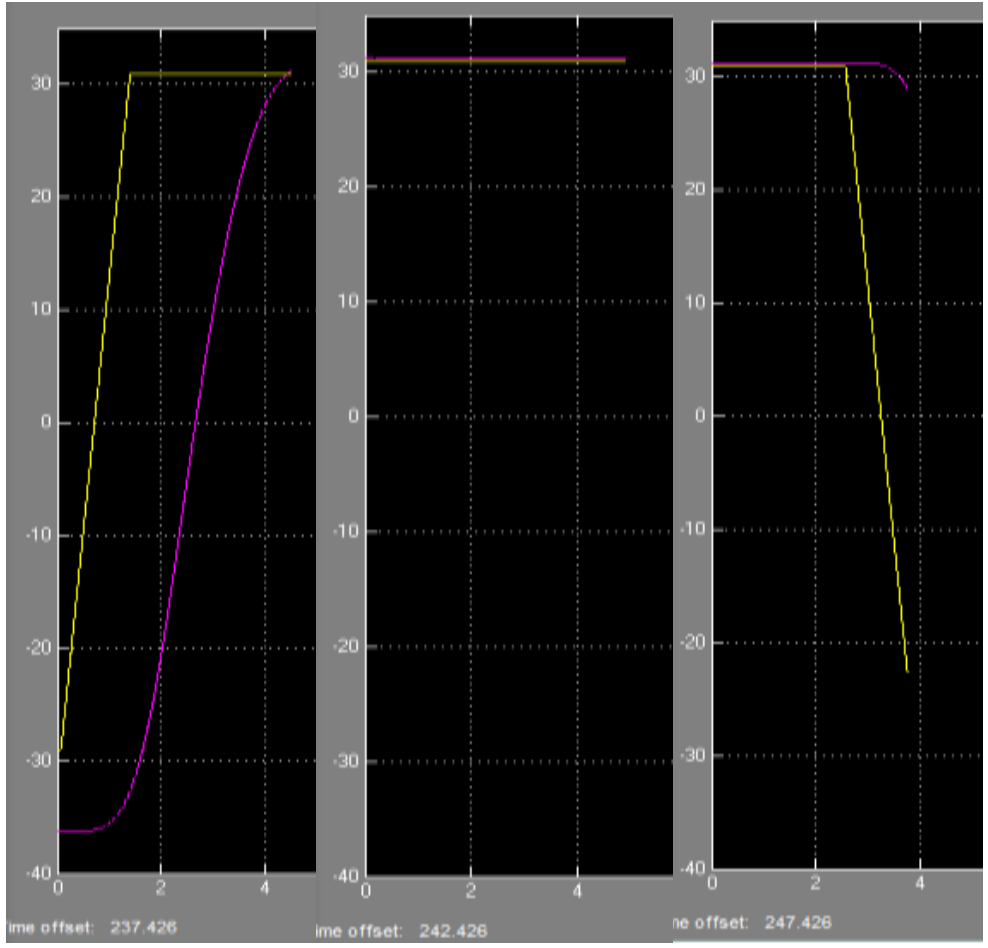

Figure 14. Actual hardware test of the proposed fuzzy logic controller at $30^{\circ}$

\section{CONCLUSIONS}

As a conclusion, the objective of this research has been achieved. Mamdani-based Fuzzy Logic Controller for travel angle control of bench-top helicopter has been developed and tested. Matlab Simulation and real hardware tests have been performed. Performance comparison between Mamdani-based Fuzzy Logic Controller and existing LQR-I controller has been made. Based on the results obtained from the simulation test for travel angle $20^{\circ}, 30^{\circ}$ and $40^{\circ}$, Fuzzy Logic Controller has shown better response than LQR-I Controller where Fuzzy Logic Controller has lower percentage overshoot, settling time and steady state error. In the $30^{\circ}$ step input test on actual hardware, the Mamdani-based Fuzzy Logic Controller is capable to track the desired angle effectively with no percentage of overshoot and no steady state error. Fuzzy Logic Controller is also proven to work very well under small variation of angle $\left(6^{\circ}, 7^{\circ}\right.$ and $8^{\circ}$ step input).

\section{ACKNOWLEDGEMENTS}

The authors would like to thank International Islamic University Malaysia (IIUM), Universiti Teknologi MARA (UiTM) Shah Alam and University of New South Wales (UNSW) for providing facilities to support the research work.

\section{REFERENCES}

[1] J. Gao, X. Xu, C. He, "A Study on the Control Methods Based on 3-DOF Helicopter Model," Journal of Computer, vol. 7(10), pp. 2526-2526, 2012.

[2] A. Mostafa, A. Rini, L. Ari, "Multiple-surface Sliding Mode Control for 3DOF Helicopter," 4th International Conference on Mechatronics (ICOM), Kuala Lumpur, 2011.

[3] NK. Arbab, Y Dai, AA Syed, XY Xu, "3DoF Model Helicopter with Hybrid Control," TELKOMNIKA Indonesian Journal of Electrical Engineering, vol. 12(5), pp. 3863-3872, 2014.

[4] MR. Rahimi, S. Hajighasemi, D. Sanaei, "Designing and Simulation for Vertical Moving Control of UAV System using PID, LQR and Fuzzy Logic," International Journal of Electrical and Computer Engineering (IJECE), vol. 3(5), pp. 651-659, 2013.

[5] A. Lermontov, L. Yokoyama, M. Lermontov, and M. A. S. Machado, "A Fuzzy Water Quality Index for Watershed Quality Analysis and Management," E. B. T.-E. M. in P. Broniewicz, Ed. Rijeka: InTech, 2011, p. Ch. 20.

[6] P. Singhala, D. N. Shah, and B. Patel, "Temperature Control using Fuzzy Logic," Int. J. Instrum. Control Syst., vol. 4, no. 1, pp. 1-10, 2014. 
[7] H. P. H. Anh, K. K. Ahn, and N. T. Nam, "Modeling Identification of the Nonlinear Robot Arm System Using MISO NARX Fuzzy Model and Genetic Algorithm," S. B. T.-R. A. Goto, Ed. Rijeka: InTech, p. Ch. 01, 2011.

[8] H. Mansor, S.B. Mohd Noor, R. M. K. Raja Ahmad, F. S. Taip, O.F. Lutfi, "Fuzzy Control of Grain Drying Process", Proceedings of the 11th International Conference on Computer Modelling and Simulation (UKSim 2009), Cambridge, England, 2009.

[9] K. Chate, O. Prado Ramírez, and C. Rengifo, "Comparative Analysis Between Fuzzy Logic Control, LQR Control with Kalman Filter and PID Control for a Two Wheeled Inverted Pendulum", Advances in Automation and Robotics Research in Latin America. Lecture Notes in Networks and Systems, vol 13, Springer Cham, 2017.

[10] C. Chen, N. Mac Parthaláin, Y. Li, C. Price, C. Quek, and Q. Shen, "Rough-fuzzy rule interpolation," Inf. Sci. $(N y)$., vol. 351, pp. 1-17, 2016.

[11] A. A. Aldair, "FPGA Based Modified Fuzzy PID Controller for Pitch Angle of Bench-top Helicopter," Iraqi J. Electr. Electron. Eng., vol. 8, no. 1.

[12] P. Hofmann, "Defuzzification strategies for fuzzy classifications of remote sensing data," Remote Sens., vol. 8, no. 6, 2016.

[13] MathWorks, “Comparison of Sugeno and Mamdani Systems,” p. 2017, 2017.

[14] A. Kaur and A. Kaur, "Comparison of Mamdani-Type and Sugeno-Type Fuzzy Inference Systems for Air Conditioning System,” Int. J. Soft Comput. Eng., vol. 2, no. 2, pp. 323-325, 2012.

[15] B. Bede, "Mathematics of fuzzy sets and fuzzy logic," Stud. Fuzziness Soft Comput., vol. 295, pp. 1-274, 2013.

[16] A. Talon and C. Curt, "Selection of appropriate defuzzification methods: Application to the assessment of dam performance," Expert Syst. Appl., vol. 70, pp. 160-174, 2017.

[17] H. Rouhparvar and A. Panahi, "A new definition for defuzzification of generalized fuzzy numbers and its application,” Appl. Soft Comput. J., vol. 30, pp. 577-584, 2015.

[18] A. H. Mohd Hairon, H. Mansor, T. S. Gunawan, and S. Khan, "Travel angle control of quanser bench-top helicopter based on Quantitative Feedback Theory technique," Indonesian Journal of Electrical Engineering and Computer Science, vol. 1, no. 2, pp. 310-318, 2016.

[19] Liu Z, Choukri Z, Shi H., "Control Strategy Design Based on Fuzzy Logic and LQR for 3-DOF Helicopter Model," International Conference on Intelligent Control and Information Processing. Dalian. 2010.

[20] H. Mansor, A.H. Zaeri,S.B. Mohd Noor, R.K. Raja Ahmad, F.S. Taip, H.I. Ali, "Design Of QFT Controller For A Bench-Top Helicopter System Model.” International Journal of Simulation System, Science \& Technology, vol. 11(5), pp. 8-16, 2010.

[21] Quanser Inc, 3 DOF Helicopter User Manual. 2012.

[22] M. K. A. Mat Esa, H. Mansor, T. S. Gunawan, Z. Janin, Proceeding of the 5th IEEE International Conference on Smart Instrumentation, Measurement and Applications (ICSIMA), 2018

[23] C. Radhika and R. Parvathi, "Intuitionistic fuzzification functions," Glob. J. Pure Appl. Math., vol. 12, no. 2, pp. 1211-1227, 2016.

[24] F. Klawonn, R. Kruse, and R. Winkler, "Fuzzy clustering: More than just fuzzification," Fuzzy Sets Syst., vol. 281, pp. 272-279, 2015.

[25] M.H. Jafri and H. Mansor and T. S. Gunawan, "Development of Fuzzy Logic Controller for Quanser Bench-Top Helicopter,” IOP Conf. Ser. Mater. Sci. Eng., vol. 260, no. 1, p. 12015, 2017.

\section{BIOGRAPHIES OF AUTHORS}


Hasmah Mansor completed her studies at the University of Salford, UK in B.Eng Electronics \& Electrical Engineering with First Class Honours. She has obtained her Master of Science and $\mathrm{PhD}$ in Control and Automation Engineering from Universiti Putra Malaysia. Currently she is an Associate Professor at Electrical and Computer Engineering Department, and starting from Jan 2017 she has been appointed as the Deputy Dean of Students Affairs, Faculty of Engineering, IIUM. She is an IEEE senior member and just been awarded as Chartered Engineer, UK in January 2019. Her research interests include instrumentation and control systems.

Mohamd Khairul Azmi Mat Esa has completed his B.Eng. (Hons) degree in ElectronicsComputer and Information Engineering, International Islamic University Malaysia (IIUM) in 2018. His research interests are in instrumentation and control. 


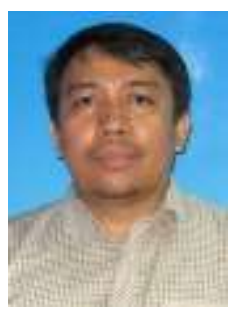

Teddy Surya Gunawan received his B.Eng degree in Electrical Engineering with cum laude award from Institut Teknologi Bandung (ITB), Indonesia in 1998. He obtained his M.Eng degree in 2001 from the School of Computer Engineering at Nanyang Technological University, Singapore, and $\mathrm{PhD}$ degree in 2007 from the School of Electrical Engineering and Telecommunications, The University of New South Wales, Australia. His research interests are in speech and audio processing, biomedical signal processing and instrumentation, image and video processing, and parallel computing. He is currently an IEEE Senior Member (since 2012), was chairman of IEEE Instrumentation and Measurement Society - Malaysia Section (2013 and 2014), Associate Professor (since 2012), Head of Department (2015-2016) at Department of Electrical and Computer Engineering, and Head of Programme Accreditation and Quality Assurance for Faculty of Engineering (2017-2018), International Islamic University Malaysia. He is Chartered Engineer (IET, UK) and Insinyur Profesional Madya (PII, Indonesia) since 2016, and registered ASEAN engineer since 2018.

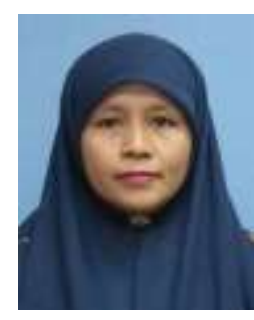

Zuriati Janin received her B. Eng in Electrical Engineering from the Universiti Teknologi Mara, Malaysia in 1996 and MSc. in Remote Sensing \& GIS from the Universiti Putra Malaysia (UPM) in 2001. In 2007, she began her study towards a Ph. D in Instrumentation and Control System at the Universiti Teknologi Mara, Malaysia. She has served as a lecturer at Universiti Teknologi Mara for more than 20 years and currently she is a Senior Lecturer at Faculty of Electrical Engineering, UiTM, Shah Alam. She has been involved with IEEE since 2012 and been mainly working with IEEE Instrumentation \& Measurement Chapter (IM09), Malaysia Section since 2013. The IM09 acknowledged her role as a founder Treasurer in initiating and promoting ICSIMA as a series of annual chapter's flagship conferences since its inception in 2013. She also has more than 10 years experiences in organizing the International Conferences, Workshops and Seminars. Her role as a conference treasurer started since 2005. 